\title{
Trends in Geographic Access to Board Certified Behavior Analysts Among Children with Autism Spectrum Disorder, 2018-2021
}

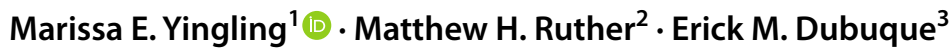 \\ Accepted: 8 December 2021 / Published online: 5 January 2022 \\ (c) The Author(s), under exclusive licence to Springer Science+Business Media, LLC, part of Springer Nature 2022
}

\begin{abstract}
Research has documented inequities in geographic access to Board Certified Behavior Analysts (BCBAs) among children with autism spectrum disorder (ASD). However, research on their accessibility is outdated. Between July 1, 2018 and July 1, 2021 the number of BCBAs in the U.S. increased by $65 \%$, from 27,320 to 45,103 . In this study we examined trends in geographic access to BCBAs among children with ASD between 2018 and 2021. The sample included all U.S. counties in 50 states and D.C. $(\mathrm{N}=3138)$. Using GIS software we examined change in county-level access to BCBAs between 2018 and 2021 and mapped ASD/BCBA ratios across all counties in both years. Study results indicate that despite modest improvements (e.g., 266 counties added BCBAs), inequitable access persists.
\end{abstract}

Keywords Autism spectrum disorder · Geographic access · Board certified behavior analysts · Applied behavior analysis

\section{Introduction}

Since the turn of the twenty-first century, the demand for applied behavior analytic (ABA) services for the treatment of autism spectrum disorder (ASD) has increased significantly (Behavior Analyst Certification Board, 2021). ABA providers implement strategies and techniques based on the principles of behavior (e.g., antecedent-based interventions, differential reinforcement, functional behavior assessment) to modify the developmental trajectory of young children with ASD (Howlin et al., 2009; Lovaas, 1987; National Autism Center, 2015; Reichow et al., 2014) as well as enhance socially significant behavior in adolescents and young adults with ASD (National Autism Center, 2015; Roth \& DiGennaro-Reed, 2014; US Department of Education, Institute for Education Sciences, 2016; Wong et al., 2014). As public and private insurance coverage for these services has expanded (Centers for Medicare and Medicaid Services,

Marissa E. Yingling

marissa.yingling@louisville.edu

1 Kent School of Social Work, University of Louisville, 2217 S 3rd St, Oppenhimer Hall, Louisville, KY 40208, USA

2 Department of Urban and Public Affairs, University of Louisville, Louisville, KY, USA

3 The Council of Autism Service Providers, Wakefield, MA, USA
2014; State Regulated Health Benefit Plans, 2020), the number of Board Certified Behavior Analysts (BCBAs)—Master's trained professionals who pass a certification examination after meeting pre-defined degree, coursework, and supervised fieldwork requirements to provide ABA services-has climbed rapidly. In 1999, there were 28 BCBAs; by July 2021, active BCBAs in the U.S. totaled 45,103.

Considering their importance in the treatment of ASD as well as empirical and anecdotal evidence that children and families have difficulty finding qualified providers (Bekker, 2018; Bump, 2017; Johnson, 2018; Lofton, 2016; Mello et al., 2016; Ovaska-Few, 2018; Yingling \& Bell, 2019; Yingling et al., 2017, 2019), several studies have examined the geographic accessibility of these practitioners. At the state level, Mcbain et al. (2020) reported an association between state health care insurance mandates for the diagnosis and treatment of ASD and an increase in BCBAs (McBain et al., 2020). In a brief report, researchers documented that the per capita supply of BCBAs fell below caseload guidelines provided by the Behavior Analyst Certification Board (BACB) (Zhang \& Cummings, 2020), and that as earlier work suggested (Deochand \& Fuqua, 2016), Northeastern states continued to have the highest per capita supply of providers. At the county level, research indicates that more than half of all counties in the United States have no BCBAs, and that the differences in access to BCBAs among children with ASD cannot be entirely explained by the county-level variation of 
ASD prevalence, suggesting that demand for the treatment of ASD does not necessarily drive the supply of BCBAs (Yingling et al., 2021a, 2021b). Furthermore, that affluent and metropolitan counties have the highest geographic access to BCBAs (Yingling et al., 2021a, 2021b).

Together, these studies document inequities in geographic access to BCBAs and provide a baseline of accessibility that previously had not existed (McBain et al., 2019). However, given the swift increase in the number of certified practitioners, research on their accessibility quickly becomes outdated. Shortly after data for the most recent of these studies was collected (Yingling et al., 2021a, 2021b; Yingling et al., 2021a, 2021b), the number of BCBAs increased by more than fifty percent. Where growth is occurring is important to understand: is the uneven distribution documented worsening, improving, or staying the same? With the goal of providing an up-to-date assessment of geographic access to ABA services for children with ASD in the U.S., the purpose of this study was to examine the distribution of recent growth in BCBAs.

\section{Method}

The study sample included all U.S. counties and county equivalents (e.g., parishes, independent cities) in all 50 states and D.C. $(\mathrm{N}=3138)$. We used two primary sources: the U.S. Department of Education's Civil Rights Data Collection (CRDC) and the BACB registry. The CRDC is utilized to evaluate access to educational opportunity for the nation's children and is published biennially-we use the most current data available (2017-2018). The CRDC includes counts of the number of children enrolled and the number of children with educational disabilities for every public school within the U.S. (United States Department of Education, 2018). The number of children with any educational disability is reported by the primary special education category. Thus, a child with a primary diagnosis of ASD and secondary diagnosis of intellectual disability (ID) will only be included in the ASD count for that school. In this study, we included only those children with a primary special education category of ASD. School enrollments and the number of children with ASD were aggregated to the school district-level.

The BACB registry includes the certification date, type, location ZIP code, and status for all certified BCBAs. Although both regular BCBAs and Board Certified Behavior Analysts-Doctorate (BCBA-D) were included in this analysis, Board Certified Assistant Behavior Analystsalso included in the registry-were not. These mid-level providers were excluded because they represent less than $10 \%$ of the BACB certificants in the U.S. (over $40 \%$ in Florida) and must be supervised by a BCBA or BCBA-D
(Behavior Analyst Certification Board, n.d.). We also excluded those BCBAs with a certification status of inactive at the time of the most recent registry release (July 2021). The BCBA registry was stratified into those providers certified prior to July 1, 2018, and those providers certified prior to July 1, 2021, and both types were aggregated within the ZIP code location.

Both the CRDC data and the BACB data lack county designations. We allocated the district count of children with ASD and the district enrollment to counties based on the percentage of the district population within each county, using the Geographic Correspondence Engine provided by the Missouri Census Data Center (Saporito et al., 2007). Similarly, we allocated the ZIP code-level BCBA counts in 2018 and 2021 to counties based on the percentage of business addresses within each county, using the HUD Office of Policy Development and Research ZIP code crosswalk files (Wilson, 2018). The ZIP codes reported for $98(0.2 \%)$ of the BCBAs were invalid, and these individuals were not counted. We obtained Institutional Review Board approval from the University of Louisville.

\section{Variables}

$A S D$ prevalence was calculated as the number of children with ASD per 1000 children enrolled in schools. We examined change in geographic access to BCBAs by comparing two measures in 2018 and 2021. First, we categorized $B C B A$ presence in each year as (1) the presence of at least one BCBA in a county, (2) no BCBAs in a county, or (3) no BCBAs in a county and no BCBAs in a bordering county. Next, for each county, we calculated the $A S D / B C B A$ ratio in each year as the quotient of the number of children with ASD divided by the number of BCBAs. The number of children with ASD as reported in the 2017-2018 CRDC is used as the numerator in both years. As such, any change in these ratios must be the result of change in the BCBA presence in the county. Note that in terms of access, lower ASD/BCBA ratios would be considered better.

Obviously, any decrease observed in the ASD/BCBA ratios is going to be overstated, since the numerator-the number of children with ASD-is not changing. Unfortunately, the substantial lag in the reporting of the CRDC data does not allow for a current count of children with ASD at the county-level nationwide. However, we note that while the number of children with ASD had been increasing nationwide by $7 \%$ per year, on average prior to 2018 , between 2018 and 2021 the number of BCBAs increased by more than $21 \%$ per year. The disproportionate gain in the number of BCBAs versus the expected number of children with ASD will mitigate this concern somewhat. 


\section{Statistical Analysis}

We used GIS software to examine change in county-level geographic access to BCBAs in the U.S. between 2018 and 2021. We mapped ASD/BCBA ratios across all counties in both 2018 and 2021, using the same modified Natural Breaks classification in both years to maintain comparability. Because the CRDC data from the state of Iowa does not report disability type by county, Iowa county rates are missing in the maps. We visually inspected the maps for geographic differences, generated county-level correlation coefficients between the two years, and calculated statistics describing the BCBA distribution and access in greater detail. Although community involvement was not required to complete this study, a social worker and BCBA-D with extensive experience in the field are authors.

\section{Results}

Table 1 includes the descriptive statistics of outcome variables. In July 2018 more than half of all counties (54\%, $n=1696$ ) had no BCBAs; of these, 374 bordered counties with no BCBAs. By July 2021, this number had declined by $10 \%$; a little less than half of all counties $(46 \%, n=1430)$ had no BCBAs and of these, 256 bordered counties with no BCBAs. Depicted in Fig. 1 are the 266 counties which moved from zero to at least one BCBA between 2018 and 2021. These counties were

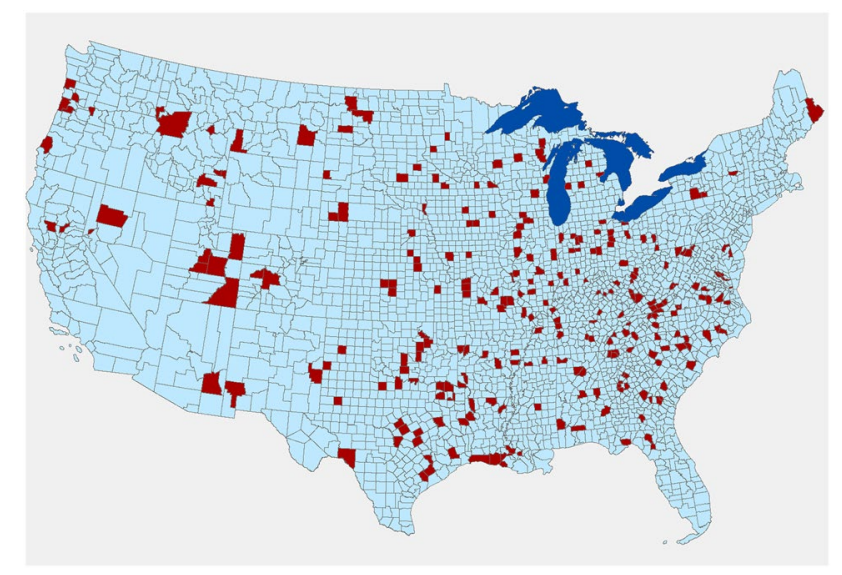

Fig. 1. 266 Counties (in red) Gained Board Certified Behavior Analysts between 2018 and 2021

geographically dispersed, although unsurprisingly, they had a mean population greater than those that remained with zero BCBAs $(33,807$ vs. 15,628$)$. In general, BCBA growth was strongly associated with the existing presence of BCBAs. Figure 2 displays a scatterplot of the BCBA count in 2018 and the BCBA count in 2021 for all 3138 counties. Note that the three counties with more than 500 BCBAs in 2018 are truncated from this plot to allow for greater detail at the lower end of the scale. The Pearson correlation between the BCBA counts in 2018 and 2021 (excluding the 1,430 counties which had a count of 0 in
Table 1 Descriptive statistics for prevalence of autism spectrum disorder and distribution of board certified behavior analysts in 2018 and $2021(\mathrm{~N}=3138)$

\begin{tabular}{|c|c|c|c|c|c|c|c|c|}
\hline \multirow[t]{2}{*}{ Variable } & \multicolumn{4}{|l|}{2018} & \multicolumn{4}{|l|}{2021} \\
\hline & $\mathrm{n}$ & $\%$ & Mean & Median & $\mathrm{n}$ & $\%$ & Mean & Median \\
\hline$B C B A$ presence ${ }^{\mathrm{a}}$ & & & 8.7 & 0.0 & & & 14.3 & 1.0 \\
\hline At least $1 \mathrm{BCBA}$ & 1442 & 46.0 & & & 1708 & 54.4 & & \\
\hline $\begin{array}{l}\text { No BCBAs, } \\
\text { BCBAs in Border- } \\
\text { ing County }\end{array}$ & 1696 & 42.1 & & & 1430 & 37.4 & & \\
\hline $\begin{array}{l}\text { No BCBAs, No } \\
\text { BCBAs in Border- } \\
\text { ing Counties }\end{array}$ & 374 & 11.9 & & & 256 & 8.2 & & \\
\hline$A S D / B C B A$ ratio $^{\mathrm{b}}$ & & & 38.6 & 27.0 & & & 27.2 & 18.8 \\
\hline No BCBAs & 1623 & 53.4 & & & 1361 & 44.8 & & \\
\hline $0-9.9$ & 170 & 5.6 & & & 379 & 12.5 & & \\
\hline $10-24.9$ & 497 & 16.4 & & & 679 & 22.3 & & \\
\hline $25-49.9$ & 435 & 14.3 & & & 405 & 13.3 & & \\
\hline $50-99.9$ & 236 & 7.8 & & & 170 & 5.6 & & \\
\hline $100+$ & 78 & 2.6 & & & 45 & 1.5 & & \\
\hline ASD not reported & 99 & & & & 99 & & & \\
\hline
\end{tabular}

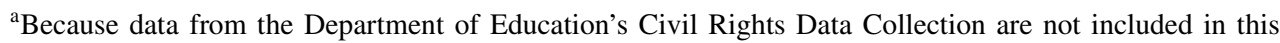
measure, Iowa counties are included in this measure

${ }^{b}$ Percentages may not sum to 100 due to rounding. 26 counties in Iowa (in 2018) and 30 counties in Iowa (in 2021) have BCBAs but did not report CRDC data 


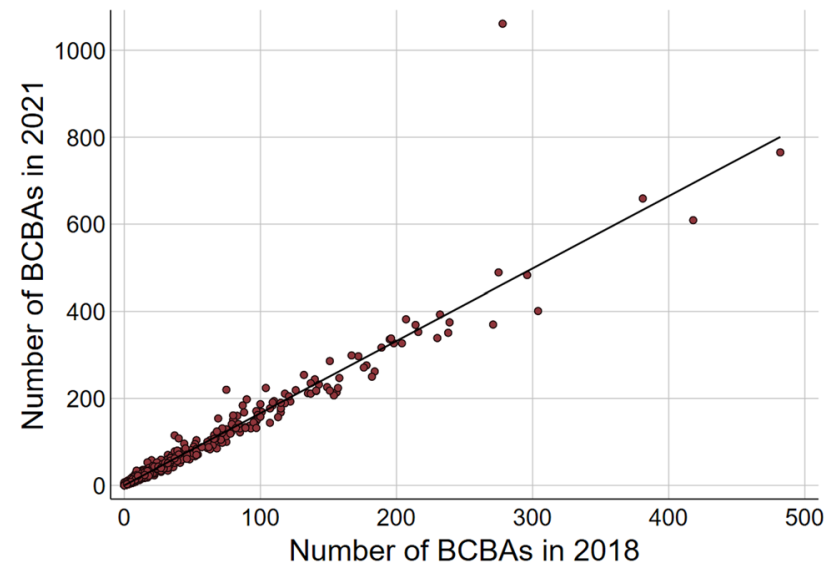

Fig. 2 Scatterplot of the Board Certified Behavior Analysts count in 2018 and in 2021

both years) was $0.9796(\mathrm{p}<0.000)$. The Spearman correlation was $0.9379(\mathrm{p}<0.000)$.

Figure 3 shows the ASD/BCBA ratio across U.S. counties classified using the same break points in 2018 and 2021. The number of counties in the greatest access category-with fewer than 10 children with ASD per BCBA-increased from 170 in 2018 to 379 in 2021 , while the number of counties in the two lowest access categories-with greater than 50 children with ASD per BCBA-declined from 314 to 215 . Of the 608 counties in the highest quintile of ASD prevalence ( $\geq 12.36$ children with ASD per 1000 enrolled), 197 (32.4\%) had no BCBAs in 2018 and 153 (25.2\%) had no BCBAs in 2021. Of the 304 counties in the highest decile of ASD prevalence $(\geq 14.56$ children with ASD per 1000 enrolled), 110 (36.2\%) had no BCBAs in 2018 and 92 (30.3\%) had no BCBAs in 2021.

Overall, more than 31.3 million people and 42,546 children with ASD (7.4\% of total) lived in a county with no BCBAs in 2018. In 2021, approximately 22.3 million people and 29,297 children with ASD (5.1\% of total) lived in a county with no BCBAs. Among the 1,430 counties with no BCBAs in 2021 are several populous counties with notable state and/or local significance. These include Shawnee County (Topeka), Kansas (2020 Population $=178,909)$, Ector County (Odessa), Texas $(165,171)$, and San Juan County (Farmington), New Mexico $(121,661)$.

\section{Discussion}

Study results indicate that uneven county-level distribution of BCBAs as a function of the number of children with ASD persists, even after $65 \%$ growth in certified practitioners between July 1, $2018(27,320)$ and July 1, $2021(45,103)$. In 2021, 37.4\% $(n=1,430)$ counties had no
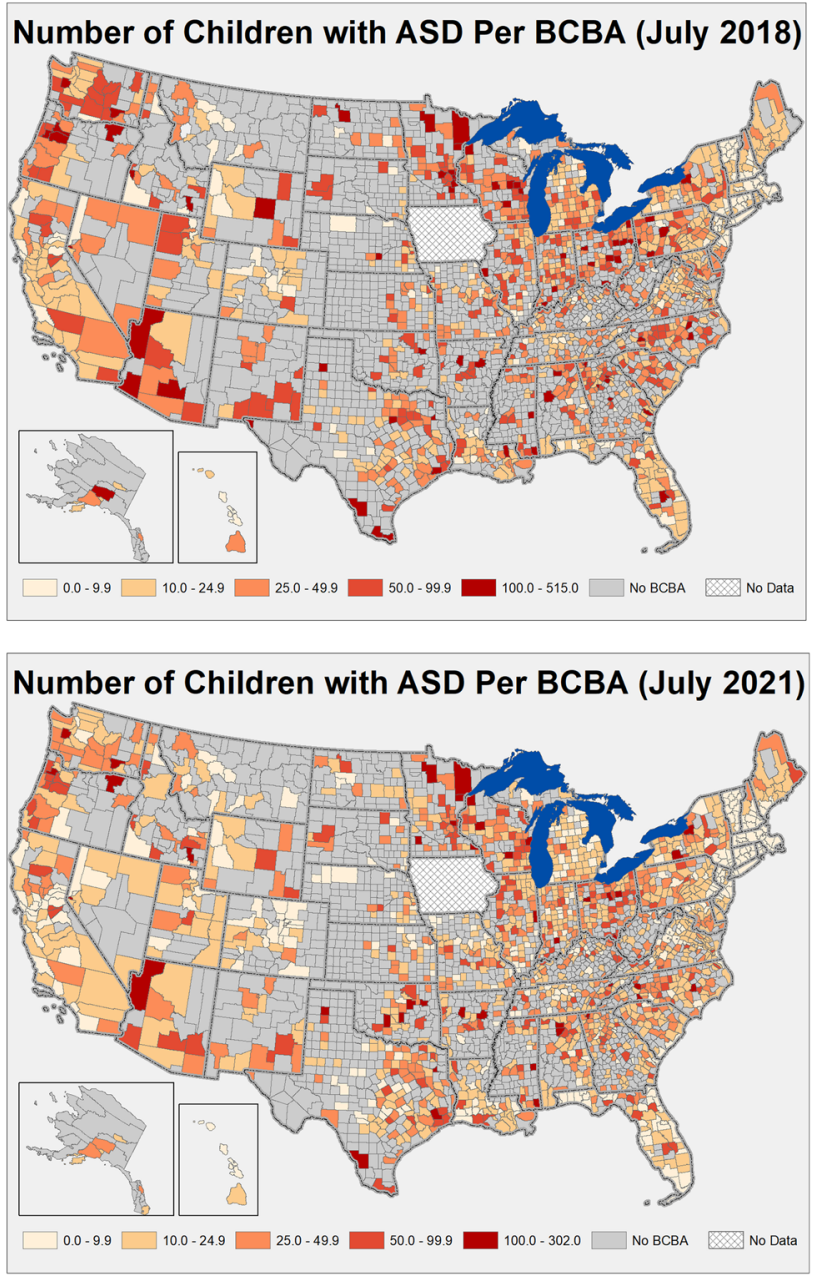

Fig. 3 Prevalence of Children with Autism Spectrum Disorder per BCBA by U.S. County Natural breaks categorization of children with ASD per 1000 children enrolled

BCBAs and $8.2 \%(\mathrm{n}=256)$ had no BCBAs and no BCBAs in bordering counties. Approximately $65 \%$ of counties had 25 or more children with ASD per BCBA, suggesting low access across the country. However, a detailed comparison between 2018 and 2021 suggests that there were modest improvements in geographic access. Perhaps the most significant development is that in three years 266 counties moved from no BCBAs to at least one BCBA. Additionally, the number of counties with fewer than 10 children with ASD per BCBA increased by 209 while the number of counties with 50 or more children with ASD per BCBA declined by 99. It is encouraging that the number of counties in the highest quintile of ASD prevalence ( $\geq 12.36$ children with ASD per 1,000 enrolled) without BCBAs declined from 197 (32.4\%) in 2018 to 153 (25.2\%) in 2021. That is, if ASD prevalence represents need, geographic access to BCBAs is improving but still falls far short of meeting counties with greatest need. 
Unsurprisingly, counties that moved from zero to at least one BCBA between 2018 and 2021 had a mean population greater than those that remained with zero BCBAs $(33,807$ vs. 15,628$)$, suggesting that non-metro counties with lower populations continue to experience lower access. This aligns with earlier findings that affluent and metropolitan counties enjoy the greatest geographic access to BCBAs (Yingling et al., 2021a, 2021b). Although metropolitan areas are generally characterized by greater access, however, some populous counties of notable significance remain without a BCBA: Shawnee County (Topeka), Kansas (2020 Population $=178,909)$, Ector County (Odessa), Texas $(165,171)$, and San Juan County (Farmington), New Mexico $(121,661)$. Determining whether children with ASD in these and other populous counties with no BCBAs are served by BCBAs in adjacent counties may be important to assess and to improve access.

Importantly, like earlier research, this study likely portrays a better scenario for geographic access among children with ASD than what exists. Among BCBAs, an estimated $73 \%$ work with individuals diagnosed with ASD (Behavior Analyst Certification Board, n.d.). Given the prevalence of ASD and the limited number of providers, in most counties, to serve children with ASD would require BCBAs to far exceed the maximum caseload recommendations (The Council of Autism Service Providers, 2020). When working with children with ASD, BCBAs commonly use treatment models that differ in recommended caseloads and corresponding dosage, or hours per week. For example, focused ABA is often recommended at 10 to $25 \mathrm{~h}$, whereas comprehensive $\mathrm{ABA}$, or early intensive behavioral intervention is often recommended for 25 to $40 \mathrm{~h}$. The recommended caseload for BCBAs depends on several factors including, "complexity and needs of the clients", "total treatment hours delivered to the clients", "total case supervision and clinical direction required by caseload", "expertise and skills of the Behavior Analyst", "location and modality of supervision and treatment (for example, center vs. home, individual vs. group, telehealth vs. in vivo)", and "availability of support staff for the Behavior Analyst (for example, a BCaBA)" (The Council of Autism Service Providers, 2020). The recommended caseload for focused treatment without the support of an assistant is 10 to 15 clients while for comprehensive treatment it is 6 to 12 . With the support of an assistant the recommended caseload is 16 to 24 and 12 to 16 , respectively. Study results suggest that this is not the case for most counties. Among counties with BCBAs, 620 had ASD/BCBA ratios of 25 to 49.9 children with ASD per BCBA $(n=405)$, 50 to 99.9 children with ASD per BCBA $(n=170)$, and 100 or greater children with ASD per BCBA $(n=45)$. That geographic access to BCBAs does not reflect recommended caseloads is the conclusion of other studies. Using 2018 BACB data and assuming that all BCBAs provide focused treatment, Zhang and Cummings (2020) documented that the per capita supply of BCBAs was below recommendations in 49 states. Given that not all BCBAs work with ASD, that not all BCBAs utilize comprehensive or focused treatment models, and that caseload size is not a straightforward metric because different patients require different dosages of treatment hours and caseload management time, geographic access is difficult to pinpoint. However, while this study shows some improvement in geographic access over time, in general it likely overestimates access. It also demonstrates how children with ASD living in rural counties who may already be at a disadvantage because they wait longer to receive a diagnosis (Daniels \& Mandell, 2014) may be further marginalized due to a lack of access to BCBAs (Yingling et al., 2021a, 2021b). This cumulative disadvantage (Lynch, 2008) has significant implications for child and family outcomes as well as the costs associated with lifelong services.

Study findings are similar to those recorded on geographic access to other health care providers; that is, access is unevenly distributed, greater access is evident in affluent and metropolitan areas, and this inequity persists (Andrilla et al., 2018; Rosenblatt et al., 2010; Shipman et al., 2011). This is despite efforts by the federal government, which has invested significantly in increasing access to healthcare providers using financial incentives (Pathman \& Konrad, 2012; Phillips et al., 2018). Given this larger context in healthcare, to expect that the U.S. will experience equitable geographic access to BCBAs in the near or distant term is impractical. Still, as the number of practitioners continues to increase, and as the issue of quality becomes a central focus of the profession (Critchfield, 2015; Silbaugh \& El Fattal, 2021), it will be important to determine where geographic gaps can be filled and in what manner (in person vs telehealth vs hybrid). To begin, professional associations and researchers representing the interests of ABA service providers could determine why 266 counties added BCBAs between 2018 and 2021 and how these developments could be promoted in other counties. Professional associations and institutions of higher education that offer applied behavior analytic training that prepare students for the BCBA examination could partner with state governments to provide educational initiatives such as tuition remission for students who commit to working in underserved areas for a certain amount of time. The prototype for this approach is the National Health Service Corps scholarship and loan repayment programs. Similarly, providers could consider home growing or transplanting BCBAs by offering tuition reimbursement to staff.

The advancement of telehealth during the COVID-19 Pandemic could help with training and mentorship opportunities for BCBAs working in more remote areas (Ninci et al., 2021). Models or guides for the delivery of ABA services via telehealth published by professional associations like the 
Council of Autism Service Providers (CASP), Association for Professional Behavior Analysts (APBA) and the Association for Behavior Analysis International (ABAI) could be useful for promoting quality services and adoption of best practices. The recently updated CASP Practice Parameters for Telehealth, Second Edition (Council of Autism Service Providers, 2021) first published at the beginning of the pandemic is one example of what could be accomplished. Additionally, as the evidence base develops for telehealth as a service-delivery mechanism for ABA services, a mandatory telehealth component of coursework offered by ABA training programs may become necessary, and providers could invest in infrastructure for quality service provision via telehealth, as reduced travel burden and shortened waitlists are well documented (Tomlinson et al., 2018). Still, telehealth is not a panacea. A BCBA attempting to provide supervision and programming remotely to an adolescent engaging in self-injurious behavior under an inexperienced RBT or caregiver, a child who constantly elopes, an RBT working on social skills at school with a child during recess, or a parent who simply wishes to take their teen to a restaurant without challenging behavior will experience the limitations of telehealth. Children most likely to experience limited access to face-to-face service delivery may also be those who are more likely to experience barriers to telehealth because of an inconsistent internet connection, lack of a computer, or lack of an adequate space for therapy.

\section{Limitations}

There are several limitations of this study. First, the lack of current (2021) CRDC data highlighted above-in conjunction with the limitation of the CRDC data in capturing children with ASD not enrolled in public schools-suggests that our estimates of access (ASD/BCBA ratios) are too low. States only report children's primary educational disability. Therefore, it is possible that some children have a secondary educational disability of ASD and a different primary educational disability, such as ID. Indeed, states vary in eligibility requirements for a primary disability of ASD (MacFarlane \& Kanaya, 2009). However, the CRDC provides the best data available to estimate prevalence of ASD, and it does appear that this data yields modest differences in county-level geographic access when accessibility of children with a primary national educational disability of ASD only are compared to children with a primary educational disability of ASD and of ID (Yingling et al., 2021a, 2021b). Further details about the limitations of the CRDC data related to children with ASD have been recorded elsewhere (Yingling et al., 2021a, 2021b).

Another limitation is that details about the caseloads of individual BCBAs are not included in the BACB data. Some BCBAs may maintain their credential but not actively practice, such as academicians and administrators, and some BCBAs may work exclusively with children who are diagnosed with ASD, carry a mixed caseload of children with ASD and other populations, or work only with other populations. Data also were unavailable on which treatment models BCBAs use, the size of their caseloads, and the number of hours spent supervising. Relatedly, the county in which individual BCBAs provide treatment may be different from the county in which they reside, which could lead to higher or lower ASD/BCBA ratios, and some BCBAs provide telehealth services, which are not accounted for in this study.

\section{Conclusion}

Despite improvements between July 1, 2018 and July 1, 2021, uneven county-level geographic access to BCBAs among children with ASD persists. Future research by professional associations and scholars that identifies why modest improvements occurred may be important for making progress in many geographic areas, particularly those areas with lowest access. It may also be worthwhile for professional associations to explore and advocate for state educational initiatives and training as well as employer incentives to improve access.

Author Contributions MY conceived of the study, led its design and coordination, drafted the initial manuscript, and finalized the manuscript; MR contributed to design and conceptualization, conducted analyses, drafted the methods and results, and provided feedback on manuscript drafts. EM contributed to study design and conceptualization, provided expertise especially in the discussion, and offered feedback on manuscript drafts. All authors read and approved the final manuscript.

Funding This study received no funding.

\section{Declarations}

Conflict of interest Dr. Marissa E. Yingling declares that she has no conflict of interest. Dr. Matthew H. Ruther declares that he has no conflict of interest. Dr. Erick M. Dubuque declares that he has no conflict of interest.

\section{References}

Andrilla, C. H. A., Patterson, D. G., Garberson, L. A., Coulthard, C., \& Larson, E. H. (2018). Geographic variation in the supply of selected behavioral health providers. American Journal of Preventive Medicine, 54(6), S199-S207. https://doi.org/10.1016/j. amepre.2018.01.004 
Behavior Analyst Certification Board. (n.d.). BACB certificant data. Retrieved March 14, 2019, from https://www.bacb.com/bacb-certi ficant-data.

Behavior Analyst Certification Board. (2021). US employment demand for behavior analysts: 2010-2020.

Bekker, J. (2018). Las Vegas families describe waiting game for Autism therapy. Las Vegas Review-Journal.

Bump, B. (2017). A safe haven for autistic children: Crossroads Center uses applied behavior analysis to "reinforce positive" actions. Times Union. Retrieved from https://www.timesunion.com/living/ article/A-safe-haven-for-autistic-children-12357167.php.

Centers for Medicare and Medicaid Services. (2014). Medicaid and CHIP FAQs: Services to address Autism. Department of Health and Human Services. Retrieved from http://www.medicaid.gov/ federal-policy-guidance/downloads/faq-09-24-2014.pdf.

Council of Autism Service Providers. (2021). Practice parameters for telehealth-implementation of Applied Behavior Analysis, Second Edition. Retrieved from http://casproviders.org/wpcontent/uploads/2021/12/Final-Copy-Practice-Parameters-Teleh ealth-ABA-AMA-References-12.2.2199.pdf.

Critchfield, T. S. (2015). In dreams begin responsibility: Why and how to measure the quality of graduate training in applied behavior analysis. Behavior Analysis in Practice, 8, 123-133.

Daniels, A. M., \& Mandell, D. S. (2014). Explaining differences in age at autism spectrum disorder diagnosis: A critical review. Autism, 18(5), 1-15. https://doi.org/10.1177/1362361313 480277

Deochand, N., \& Fuqua, R. W. (2016). BACB certification trends: State of the states (1999 to 2014). Behavior Analysis in Practice, 9(3), 243-252. https://doi.org/10.1007/s40617-016-0118-z

Howlin, P., Magiati, I., \& Charman, T. (2009). Systematic review of early intensive behavioral interventions for children with autism. American Journal on Intellectual and Developmental Disabilities, 114(1), 23-41. https://doi.org/10.1352/2009.114:23-41

Johnson, S. (2018). Medicaid coverage of autism therapy to expand; provider shortage may still limit access. WV Metro News. Retrieved from http://wvmetronews.com/2018/04/30/medic aid-coverage-of-autism-therapy-to-expand-provider-short age-may-still-limit-access/.

Lofton, K. L. (2016). Autism services lacking for West Virginia families. West Virginia Public Broadcasting. Retrieved from http:// www.wvpublic.org/post/autism-services-lacking-west-virginiafamilies.

Lovaas, O. I. (1987). Behavioral treatment and normal educational and intellectual functioning in young autistic children. Journal of Consulting and Clinical Psychology, 55(1), 3.

Lynch, S. M. (2008). Race, socioeconomic status, and health in lifecourse perspective: Introduction to the special issue. Research on Aging, 30(2), 127-136. https://doi.org/10.1177/0164027507 312086

MacFarlane, J. R., \& Kanaya, T. (2009). What does it mean to be Autistic? Inter-state variation in special education critieria for Autism services. Journal of Child and Family Studies, 18(6), 662-669.

McBain, R. K., Cantor, J. H., Stein, B. D., \& Yu, H. (2020). State insurance mandates and the workforce for children with autism. Pediatrics, 146(4), e20200836. https://doi.org/10.1542/peds.2020-0836

McBain, R. K., Kareddy, V., Cantor, J. H., Stein, B. D., \& Yu, H. (2019). Systematic review: United States workforce for Autismrelated child healthcare services. Journal of the American Academy of Child \&amp; Adolescent Psychiatry. https://doi.org/10. 1016/j.jaac.2019.04.027

Mello, M. P., Urbano, R. C., Goldman, S. E., \& Hodapp, R. M. (2016). Services for children with autism spectrum disorder: Comparing rural and non-rural communities. Education and Training in Autism and Developmental Disabilities, 51(4), 355.
National Autism Center. (2015). Findings and conclusions: National standards project, phase 2. National Autism Center.

Ninci, J., Čolić, M., Hogan, A., Taylor, G., Bristol, R., \& Burris, J. (2021). Maintaining effective supervision systems for trainees pursuing a Behavior Analyst Certification Board Certification during the COVID-19 Pandemic. Behavior Analysis in Practice. https://doi.org/10.1007/s40617-021-00565-9

Ovaska-Few, S. (2018). N.C.'s shortage of autism therapists leaves some on Medicaid waiting months, even years. North Carolina Health News. Retrieved from https://www.northcarolinahealthnews.org/ 2018/05/01/north-carolinas-shortage-of-autism-specialists-leavessome-on-medicaid-waiting-months-even-years-for-help/.

Pathman, D. E., \& Konrad, T. R. (2012). Growth and changes in the National Health Service Corps (NHSC) Workforce with the American Recovery and Reinvestment Act. The Journal of the American Board of Family Medicine, 25(5), 723-733. https://doi. org/10.3122/jabfm.2012.05.110261

Phillips, J., Edwards-Johnson, J., \& Wendling, A. (2018). US federal policies should better support the primary care physician workforce. Family Medicine, 50(1), 7-9. https://doi.org/10.22454/ FamMed.2018.784272

Reichow, B., Barton, E., Boyd, B., \& Hume, K. (2014). Early intensive behavioral intervention (EIBI) for young children with autism spectrum disorders (ASD): A systematic review. Campbell Systematic Reviews. Retrieved from http://www.campbellcollabo ration.org/lib/project/338/.

Rosenblatt, R., Chen, F., Lishner, D., \& Doescher, M. (2010). The future of family medicine and implications for rural primary care physician supply (Final Report \#125). WWAMI Rural Health Research Center, University of Washington School of Medicine Department of Family Medicine. Retrieved from https://depts. washington.edu/uwrhrc/uploads/RHRC_FR125_Rosenblatt.pdf.

Roth, M., \& DiGennaro-Reed, F. (2014). A meta-analysis of behavioral interventions for adolescents and adults with Autism Spectrum Disorders. Journal of Behavioral Education, 23, 258-286.

Saporito, S., Chavers, J., Nixon, L., \& McQuiddy, M. (2007). Frome here to there: Methods of allocating data between census geography and socially meaningful areas. Social Science Research, 36(3), 897-920.

Shipman, S. A., Lan, J., Chang, C.-H., \& Goodman, D. C. (2011). Geographic maldistribution of primary care for children. Pediatrics, 127(1), 19-27. https://doi.org/10.1542/peds.2010-0150

Silbaugh, B. C., \& El Fattal, R. (2021). Exploring quality in the applied behavior analysis service delivery industry. Behavior Analysis in Practice. https://doi.org/10.1007/s40617-021-00627-y

State regulated health benefit plans. (2020). Autism Speaks. Retrieved from https://www.autismspeaks.org/state-regulated-health-benef it-plans.

The Council of Autism Service Providers. (2020). Applied behavior analysis treatment of autism spectrum disorder: Practice guidelines for healthcare funders and managers (2nd ed). Retrieved from https://casproviders.org/wp-content/uploads/2020/03/ABAASD-Practice-Guidelines.pdf.

Tomlinson, S. R. L., Gore, N., \& McGill, P. (2018). Training individuals to implement Applied Behavior Analytic procedures via telehealth: A systematic review of the literature. Journal of Behavioral Education, 27(2), 172-222. https://doi.org/10.1007/ s10864-018-9292-0

United States Department of Education. (2018). 2017-2018 Civil Rights Data Collection: List of CRDC data elements for school year 2017-2018. Retrieved from https://www2.ed.gov/about/offic es/list/ocr/docs/2017-18-crdc-data-elements.pdf.

US Department of Education, Institute for Education Sciences. (2016). Functional behavioral assessment-based interventions. What Works Clearinghouse. Retrieved from https://ies.ed.gov/ncee/ wwc/Intervention/1241. 
Wilson, R. (2018). Understanding and enhancing the U.S. Department of Housing and Urban Development's ZIP Code Crosswalk Files. Cityscape: A Journal of Policy Development and Research, 20(2), 277-294.

Wong, C., Odom, S. L., Hume, K., Cox, A. W., Fettig, A., Kucharczyk, S., Brock, M. E., Plavnick, J., Fleury, V., \& Schultz, T. (2014). Evidence-based practices for children, youth, and young adults with Autism Spectrum Disorder. The University of North Carolina, Frank Porter Graham Child Development Institute, Autism Evidence-Based Practice Review Group.

Yingling, M. E., \& Bell, B. A. (2019). Underutilization of early intensive behavioral intervention among 3-year-old children with Autism Spectrum Disorder. Journal of Autism and Developmental Disorders. https://doi.org/10.1007/s10803-019-04005-0

Yingling, M. E., Bell, B. A., \& Hock, R. M. (2019). Treatment utilization trajectories among children with autism spectrum disorder: Differences by race-ethnicity and neighborhood. Journal of Autism and Developmental Disorders, 49(5), 2173-2183. https:// doi.org/10.1007/s10803-019-03896-3

Yingling, M. E., Hock, R. M., Cohen, A., \& McCaslin, E. (2017). Parent perceived challenges to treatment utilization in a publicly funded early intensive behavioral intervention program for children with Autism Spectrum Disorder. International Journal of
Developmental Disabilities. https://doi.org/10.1080/20473869. 2017.1324352

Yingling, M. E., Ruther, M. H., Dubuque, E. M., \& Bell, B. A. (2021a). Impact of county sociodemographic factors and state policy on geographic access to behavior analysts among children with autism spectrum disorder. Administration and Policy in Mental Health and Mental Health Services Research. https://doi.org/10. 1007/s10488-021-01120-y

Yingling, M. E., Ruther, M. H., Dubuque, E. M., \& Mandell, D. S. (2021b). County-level variation in geographic access to Board Certified Behavior Analysts among children with Autism Spectrum Disorder in the United States. Autism, 25(6), 1734-1745. https://doi.org/10.1177/13623613211002051

Zhang, Y., \& Cummings, J. (2020). Supply of certified applied behavior analysts in the United States: Implications for service delivery for children with autism. Autism, 71(4), 385-388. https://doi.org/10. 1176/appi.ps.201900058

Publisher's Note Springer Nature remains neutral with regard to jurisdictional claims in published maps and institutional affiliations. 